\section{Commentary: Delaying the inevitable? Interventions for medically managed, uncomplicated type B aortic dissection}

\author{
James A. Brown, MA, ${ }^{a}$ and Ibrahim Sultan, MD $^{\mathrm{a}, \mathrm{b}}$
}

Thoracic endovascular aortic repair (TEVAR) is the recommended treatment for patients presenting with acute type $B$ aortic dissection (ATBAD) that is complicated by rupture or malperfusion, whereas optimal medical therapy (OMT) is recommended for uncomplicated ATBAD. ${ }^{1-5}$ However, some data suggest that some uncomplicated ATBAD (ie, without rupture or malperfusion) may deserve early endovascular intervention. ${ }^{6-12}$ Much of the uncertainty derives from a dearth of robust natural history data that describes the high-risk features for long-term aneurysmal degeneration, aortic rupture, and sudden death. There are also minimal data describing the incidence, outcomes, and risk factors of late aortic intervention after OMT for uncomplicated ATBAD. ${ }^{13,14}$ Furthermore, the few prospective trials and observational studies that directly compare OMT with TEVAR for uncomplicated ATBAD tend to be underpowered, and they tend to analyze heterogenous patient populations (eg, acute vs subacute) while targeting diverse outcomes (ie, late intervention vs aortic remodeling vs mortality) over differing time frames (ie, early vs late)..$^{6-12}$ Given the difficulties in comparing the results of these

From the a Division of Cardiac Surgery, Department of Cardiothoracic Surgery, University of Pittsburgh; and ${ }^{\mathrm{b}} \mathrm{Heart}$ and Vascular Institute, University of Pittsburgh Medical Center, Pittsburgh, Pa.

Disclosures: I.S. receives institutional research support from Medtronic and AtriCure. These conflicts are unrelated to this article. J.A.B. reported no conflicts of interest.

The Journal policy requires editors and reviewers to disclose conflicts of interest and to decline handling or reviewing manuscripts for which they may have a conflict of interest. The editors and reviewers of this article have no conflicts of interest.

Received for publication April 12, 2021; revisions received April 12, 2021; accepted for publication April 13, 2021; available ahead of print April 21, 2021.

Address for reprints: Ibrahim Sultan, MD, Division of Cardiac Surgery, Department of Cardiothoracic Surgery, University of Pittsburgh Center for Thoracic Aortic Disease, Heart and Vascular Institute, University of Pittsburgh Medical Center, 5200 Centre Ave, Suite 715, Pittsburgh, PA 15232 (E-mail: sultani@upmc.edu).

J Thorac Cardiovasc Surg 2023;165:966-9

$0022-5223 / \$ 36.00$

Copyright (c) 2021 by The American Association for Thoracic Surgery

https://doi.org/10.1016/j.jtcvs.2021.04.044

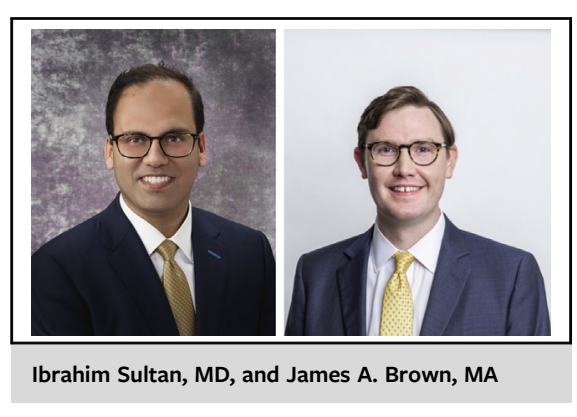

CENTRAL MESSAGE

The incidence of late surgical and endovascular interventions may be substantial for medically managed, uncomplicated dissections of the descending thoracic aorta.

handful of studies, the optimal initial management (TEVAR vs OMT) of uncomplicated ATBAD remains controversial.

In this issue of the Journal, Kreibich and colleagues ${ }^{15}$ present the incidence, outcomes, and risk factors for late aortic intervention in a cohort of medically managed, uncomplicated dissections of the descending thoracic aorta (DTA), which is an important addition to the thoracic aortic dissection literature. Crucially, this study's population includes aortic dissections of the DTA with or without aortic arch involvement. Nevertheless, all of these patients were initially managed with OMT and were discharged after their index admission for their initial presentation of the dissection. At 1 and 3 years, the risk for aortic intervention was $27 \% \pm 10 \%$ and $36 \% \pm 11 \%$, respectively. Among the 30 patients requiring intervention, two-thirds had intervention for rapid aortic growth ( $\geq 5 \mathrm{~mm}$ within 1 year), whereas the remainder had intervention for persistent symptoms or aortic rupture. TEVAR ( \pm left carotid to subclavian bypass) was performed in 25 patients $(83 \%)$, whereas the remaining 5 patients $(17 \%)$ underwent open surgical repair because of comorbid connective tissue disease. Moreover, to account for the competing event of death, the authors employed a competing risk regression analysis to determine risk factors of late aortic intervention. For the entire cohort of patients, they found that the only predictor of late aortic intervention after discharge was having a maximum DTA diameter $\geq 45 \mathrm{~mm}$ on the diagnostic computed tomography angiography. For the group of patients requiring an aortic 
intervention, there was no observed in-hospital mortality, and there was only one permanently disabling neurologic event. The authors should be congratulated for reporting this valuable data concerning the natural history of medically managed, uncomplicated dissection of the DTA, as well as their superb outcomes after late aortic intervention.

With certain critical qualifications, initial evidence from the INSTEAD (Investigation of Stent Grafts in Aortic Dissection) and ADSORB (Acute Dissection Stentgraft or Best Medical Treatment) trials indicated that TEVAR does not improve short-term survival for patients with uncomplicated ATBAD, as compared with OMT. ${ }^{4,5}$ However, 5-year follow-up data from INSTEAD-XL suggests that TEVAR may confer long-term survival benefit while reducing aorta-related mortality, improving disease progression, and augmenting positive aortic remodeling. ${ }^{6}$ Other observational data suggest similar long-term benefits. ${ }^{7-12,16-19}$ By implication, whereas OMT may safely delay disease progression, ${ }^{3}$ it does not prevent disease progression, nor does it promote positive aortic remodeling. Moreover, considering the substantial rate of late aortic interventions reported in the present study $(36 \% \pm 11 \%)$ as well as previous studies $(40 \%-45 \%),{ }^{13,14}$ OMT often nevertheless results in endovascular intervention. To be sure, interventional delay potentially avoids the risks of morbidity and mortality associated with TEVAR itself. However, interventional delay may also allow for rapid expansion of the dissected aorta, potentially leading to rupture and death. Thus, when considering late adverse events, the situation is far from clear. This begs the critical question: Are there patients who may benefit from early TEVAR to mitigate the risk of late death from disease progression and fatal rupture, despite the inherent risk of TEVAR itself?

In the present study by Kreibich and colleagues, only 1 patient required late aortic intervention for aortic rupture, and there was no in-hospital mortality for patients with late aortic intervention. This supports the concept that OMT is likely to be safe for patients with uncomplicated dissection of the DTA. While this is an encouraging result, other data are not so optimistic. The incidence of late rupture is estimated to be as high as $9 \%$, and rupture is a significant predictor of late mortality for patients with dissection of the DTA. ${ }^{3,20-22}$ In the present study, while competing risk regression helpfully isolated the cause-specific risk for aortic intervention, the sample size was small $(\mathrm{n}=91)$, and 3-year follow-up was incomplete for an unidentified number of patients, thereby limiting our ability to adequately assess the overall risks of rupture and death. As the INSTEAD-XL trial demonstrates, the natural history of aneurysmal degeneration of the dissected DTA requires at least 5 years of follow-up. Other subacute complications after ATBAD potentially include radiologic or clinical malperfusion, which is also associated with late morbidity and mortality. ${ }^{22}$ Indeed, in the present study, 7 of the 91 total patients had late-onset dynamic obstruction leading to late aortic intervention. Interestingly, the median time to aortic intervention was 4 months (interquartile range 2,11 ), which means that a substantial number of patients required intervention before their routine 6-month follow-up visit. While the authors do not comment, the optimal surveillance paradigm for patients with chronic dissection of the DTA deserves further investigation. Finally, it should be emphasized that there was no direct comparison of early OMT with early aortic intervention to assess the impact of delayed intervention on disease progression and long-term survival, as assessed in other studies. ${ }^{6-9}$ Thus, while the present study is an excellent descriptive analysis of the natural history of uncomplicated dissection of the DTA, the normative implications for the optimal surveillance regimen and the potential indication of early "prophylactic" TEVAR are far from clear.

Some uncomplicated ATBADs (ie, without rupture or malperfusion) may benefit from early endovascular intervention. As such, a new analytic category has recently emerged - the so-called "high-risk" category-for determining potential beneficiaries of early TEVAR among uncomplicated ATBADs. ${ }^{23-25}$ The 2020 Society for Vascular Surgery and Society of Thoracic Surgeons reporting guidelines argue that type B aortic dissections should encompass tears originating in the arch, as well as tears originating in the DTA but also have retrograde dissection of the arch (but without ascending aorta involvement). ${ }^{23}$ Moreover, the 2020 guidelines define high-risk type B dissections as including uncontrolled pain, refractory hypertension, bloody pleural effusion, aortic diameter $>40 \mathrm{~mm}$, radiographic evidence of arterial obstruction without clinical signs or symptoms of malperfusion syndrome, entry tears involving the lesser curve of the DTA, false lumen diameter $>22 \mathrm{~mm}$, and even 30-day hospital readmission. ${ }^{23}$ Since these features do not necessarily cohere with previous guidelines and previous studies, it remains unclear if this socalled "high-risk" category of ATBAD may benefit from early TEVAR, as opposed to OMT. Nevertheless, it is certain that many of these characteristics have been associated with disease progression, late aortic intervention, and death.

The present study adds to our knowledge concerning potential high-risk features. Patients requiring late intervention had no false lumen thrombosis, longer extent of their dissection, more re-entry tears, and closer proximity of the intimal tear to the left subclavian artery. However, on multivariable competing risk regression analysis, the only significant variable for predicting late aortic intervention was maximum aortic diameter exceeding $45 \mathrm{~mm}$. This confirms most previous literature, although some studies have identified $40 \mathrm{~mm}$ as the high-risk cutoff. ${ }^{24}$ However, when isolating the subgroup of patients without aortic arch involvement, younger age is also predictive, whereas 
distance of the left subclavian artery to the first aortic entry and the length of dissection may demonstrate trends towards predicting intervention. Young age is likely associated with connective tissue disease, but the authors do not comment on this relationship. However, again, small sample size may have limited the ability for robustly determining the effects of various predictors, such as entry tear distance from the left subclavian artery. Another potential high-risk feature that has been described in previous reports includes non-A non-B aortic dissection (aortic arch dissections). ${ }^{26-30}$ Previous reports are conflicting, ${ }^{26}$ with some describing aortic arch involvement as being high risk, ${ }^{29,30}$ whereas others do not. ${ }^{28}$ This may have to do with upfront treatment of these patients with total arch replacements with frozen elephant trunks. The present study groups include dissections of the DTA, with or without aortic arch involvement, which should prompt caution when interpreting these results. Moreover, the present study was unable to analyze the non-A non-B group alone, presumably due to sample size limitations, further limiting our ability to assess the unique risks of late aortic intervention amongst the various subtypes of ATBAD. Despite these critical observations, it is clear that maximum DTA diameter exceeding $45 \mathrm{~mm}$ is associated with high risk for late aortic intervention.

In conclusion, this study adds valuable considerations for the optimal management of uncomplicated dissection of the DTA. While the need for late aortic intervention may be substantial $(36 \% \pm 11 \%)$, the outcomes of delayed aortic intervention are encouraging, since there was no inhospital mortality and only one late rupture in the present study. Patients with maximum DTA diameter exceeding $45 \mathrm{~mm}$ on diagnostic computed tomography angiography were high risk for late aortic intervention. In the final analysis, however, it should be emphasized that this study assesses risk factors for aortic intervention, as opposed to adverse events, such as rupture or death, which are arguably the most clinically meaningful outcome measures. Thus, as the study is currently designed, the competing risk of rupture and death remains unclear. However, the fact that only 3 patients had late mortality in this cohort-treated under the conservative paradigm of initial OMT with delayed TEVAR as needed-is certainly reassuring.

\section{References}

1. Hiratzka LF, Bakris GL, Beckman JA, Bersin RM, Carr VF, Casey DE Jr, et al. 2010 ACCF/AHA/AATS/ACR/ASA/SCA/SCAI/SIR/STS/SVM Guidelines for the diagnosis and management of patients with thoracic aortic disease. $J$ Am Coll Cardiol. 2010;55:e27-129.

2. Erbel R, Aboyans V, Boileau C, Bossone E, Bartolomeo RD, Eggebrecht H, et al. 2014 ESC Guidelines on the diagnosis and treatment of aortic diseases. Eur Heart J. 2014;35:2873-926.

3. Estrera AL, Miller CC III, Safi HJ, Goodrick JS, Keyhani A, Porat EE, et al. Outcomes of medical management of acute type B aortic dissection. Circulation. 2006;114(1 suppl):I384-9.

4. Brunkwall J, Kasprzak P, Verhoeven E, Heijmen R, Taylor P, ADSORB Trialists, et al. Endovascular repair of acute uncomplicated aortic type B dissection pro- motes aortic remodelling: 1 year results of the ADSORB trial. Eur J Vasc Endovasc Surg. 2014;48:285-91.

5. Nienaber CA, Rousseau H, Eggebrecht H, Kische S, Fattori R, Rehders TC, et al. Randomized comparison of strategies for type B aortic dissection: the INvestigation of STEnt grafts in aortic dissection (INSTEAD) trial. Circulation. 2009; 120: 2519-28.

6. Nienaber CA, Kische S, Rousseau H, Eggebrecht H, Rehders TC, Kundt G, et al. Endovascular repair of type B aortic dissection: long-term results of the randomized investigation of stent grafts in aortic dissection trial. Circ Cardiovasc Interv. 2013;6:407-16.

7. Lou X, Chen EP, Duwayri YM, Veeraswamy RK, Jordan WD Jr, Zehner CA, et al. The impact of thoracic endovascular aortic repair on long-term survival in type B aortic dissection. Ann Thorac Surg. 2018;105:31-8.

8. Iannuzzi JC, Stapleton SM, Bababekov YJ, Chang D, Lancaster RT, Conrad MF, et al. Favorable impact of thoracic endovascular aortic repair on survival of patients with acute uncomplicated type B aortic dissection. J Vasc Surg. 2018;68: 1649-55.

9. Qin YL, Wang F, Li TX, Ding W, Deng G, Xie B, et al. Endovascular repair compared with medical management of patients with uncomplicated type B acute aortic dissection. J Am Coll Cardiol. 2016;67:2835-42.

10. Fattori R, Tsai TT, Myrmel T, Evangelista A, Cooper JV, Trimarchi S, et al. Complicated acute type B dissection: is surgery still the best option? A report from the International Registry of Acute Aortic Dissection. JACC Cardiovasc Interv. 2008;1:395-402.

11. Schoder M, Czerny M, Cejna M, Rand T, Stadler A, Sodeck GH, et al. Endovascular repair of acute type B aortic dissection: long-term follow-up of true and false lumen diameter changes. Ann Thorac Surg. 2007;83:1059-66.

12. Sachs T, Pomposelli F, Hagberg R, Hamdan A, Wyers M, Giles K, et al. Open and endovascular repair of type B aortic dissection in the Nationwide inpatient sample. J Vasc Surg. 2010;52:860-6; discussion 866.

13. Lou X, Duwayri YM, Chen EP, Jordan WD Jr, Forcillo J, Zehner CA, et al. Predictors of failure of medical management in uncomplicated type B aortic dissection. Ann Thorac Surg. 2019;107:493-8.

14. Schwartz SI, Durham C, Clouse WD, Patel VI, Lancaster RT, Cambria RP, et al. Predictors of late aortic intervention in patients with medically treated type B aortic dissection. J Vasc Surg. 2018;67:78-84.

15. Kreibich M, Siepe M, Berger T, Beyersdorf F, Soschynski M, Schlett CL, et al. Intervention rates and outcomes in medically-managed uncomplicated descending thoracic aortic dissections. J Thorac Cardiovasc Surg. 2023;165:958-65.e4.

16. Sultan I, Siki MA, Bavaria JE, Dibble TR, Savino DC, Kilic A, et al. Predicting distal aortic remodeling after endovascular repair for chronic DeBakey III aortic dissection. Ann Thorac Surg. 2018;105:1691-6.

17. Sultan I, Dufendach K, Kilic A, Bianco V, Trivedi D, Althouse AD, et al. Bare metal stent use in type B aortic dissection may offer positive remodeling for the distal aorta. Ann Thorac Surg. 2018;106:1364-70.

18. Kilic A, Sultan IS, Arnaoutakis GJ, Higgins RS, Kilic A. Assessment of thoracic endografting operative mortality risk score: development and validation in 2,000 patients. Ann Thorac Surg. 2015;100:860-7.

19. Brown JA, Arnaoutakis GJ, Kilic A, Gleason TG, Aranda-Michel E, Sultan I. Medical and surgical management of acute type B aortic intramural hematoma. J Card Surg. 2020;35:2324-30.

20. Elefteriades JA, Lovoulos CJ, Coady MA, Tellides G, Kopf GS, Rizzo JA. Management of descending aortic dissection. Ann Thorac Surg. 1999;67:2002-19.

21. Tsai TT, Fattori R, Trimarchi S, Isselbacher E, Myrmel T, Evangelista A, et al. Long-term survival in patients presenting with type B acute aortic dissection: insights from the International Registry of Acute Aortic Dissection. Circulation. 2006; 114:2226-31.

22. Reutersberg B, Trenner M, Haller B, Geisbüsch S, Reeps C, Eckstein HH. The incidence of delayed complications in acute type B aortic dissections is underestimated. J Vasc Surg. 2018;68:356-63.

23. Lombardi JV, Hughes GC, Appoo JJ, Bavaria JE, Beck AW, Cambria RP, et al. Society for Vascular Surgery (SVS) and Society of Thoracic Surgeons (STS) reporting standards for type B aortic dissections. J Vasc Surg. 2020;71: 723-47.

24. Trimarchi S, Tolenaar JL, Tsai TT, Froehlich J, Pegorer M, Upchurch GR, et al. Influence of clinical presentation on the outcome of acute B aortic dissection: evidences from IRAD. J Cardiovasc Surg (Torino). 2012;53:161-8.

25. Jonker FH, Trimarchi S, Rampoldi V, Patel HJ, O'Gara P, Peterson MD, et al; International Registry of Acute Aortic Dissection (IRAD) Investigators. Aortic expansion after acute type B aortic dissection. Ann Thorac Surg. 2012; 94:1223-9. 
26. Czerny M, Schmidli J, Adler S, van den Berg JC, Bertoglio L, Carrel T, et al. Current options and recommendations for the treatment of thoracic aortic pathologies involving the aortic arch: an expert consensus document of the European Association for Cardio-Thoracic surgery (EACTS) and the European Society for Vascular Surgery (ESVS). Eur J Cardiothorac Surg. 2019;55:133-62.

27. Rylski B, Pérez M, Beyersdorf F, Reser D, Kari FA, Siepe M, et al. Acute non-A non-B aortic dissection: incidence, treatment and outcome. Eur J Cardiothorac Surg. 2017;52:1111-7.
28. Nauta FJ, Tolenaar JL, Patel HJ, Appoo JJ, Tsai TT, Desai ND, et al. Impact of retrograde arch extension in acute type B aortic dissection on management and outcomes. Ann Thorac Surg. 2016;102:2036-43.

29. Loewe C, Czerny M, Sodeck GH, Ta J, Schoder M, Funovics M, et al. A new mechanism by which an acute type B aortic dissection is primarily complicated, becomes complicated, or remains uncomplicated. Ann Thorac Surg. 2012;93:1215-22.

30. Weiss G, Wolner I, Folkmann S, Sodeck G, Schmidli J, Grabenwöer M, et al. The location of the primary entry tear in acute type B aortic dissection affects early outcome, Eur J Cardiothorac Surg. 2012:42:571-6.
See Article page 958.

\section{Commentary: Medically managed uncomplicated descending thoracic aortic dissection: Are we gambling?}

\author{
Luca Di Marco, $\mathrm{MD}, \mathrm{PhD},{ }^{\mathrm{a}}$ and \\ Michele Di Mauro, MD, PhD, MSc ${ }^{\mathrm{b}}$
}

"I believe that we do not know anything for certain, but everything probably"

Christian Huygens, XVII century

Christian Huygens (April 14, 1629 to July 8, 1695) was a Dutch physicist, mathematician, astronomer, and inventor who is widely considered one of the greatest scientists of all time and a major figure in the so-called "scientific revolution." As a mathematician, Huygens developed the theory of probability, and in 1657 he wrote his first treatise on the probability theory, "De ratiociniis in ludo aleae," presenting a systematic study on probability dealing with games of chance and the odds associated with all gaming

\footnotetext{
From the a Division of Cardiac Surgery, IRCCS, S Orsola Hospital, Azienda Ospedaliero-Universitaria di Bologna, Bologna, Italy; and ${ }^{\mathrm{b}}$ Cardio-Thoracic Surgery Unit, Heart and Vascular Centre, Maastricht University Medical Centre, Cardiovascular Research Institute Maastricht, Maastricht, The Netherlands.

Disclosures: The authors reported no conflicts of interest.

The Journal policy requires editors and reviewers to disclose conflicts of interest and to decline handling or reviewing manuscripts for which they may have a conflict of interest. The editors and reviewers of this article have no conflicts of interest.

Received for publication April 13, 2021; revisions received April 13, 2021; accepted for publication April 15, 2021; available ahead of print April 20, 2021

Address for reprints: Michele Di Mauro, MD, PhD, MSc, Cardio-Thoracic Surgery Unit, Heart and Vascular Centre, Maastricht University Medical Centre, Cardiovascular Research Institute Maastricht, P Debyelaan 25, 6202 AZ Maastricht, The Netherlands (E-mail: mdimauro1973@gmail.com).

J Thorac Cardiovasc Surg 2023;165:969-70

$0022-5223 / \$ 36.00$

Copyright (C) 2021 by The American Association for Thoracic Surgery

https://doi.org/10.1016/j.jtcvs.2021.04.035
}

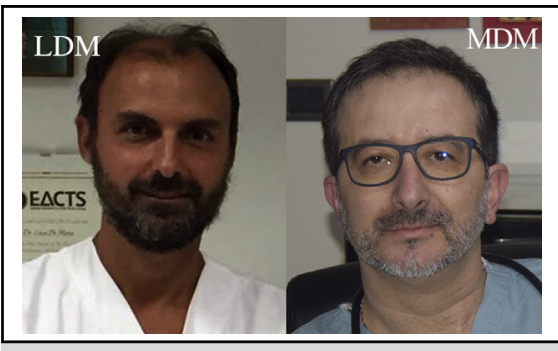

Luca Di Marco, MD, PhD, and Michele Di Mauro, MD, PhD, MSc

\section{CENTRAL MESSAGE}

The authors identify the anatomic characteristics of patients undergoing late aortic interventions and the predictive risk factors for aortic interventions.

events. Huygens' theories and subsequent use of expectation values are considered the basis of the modern concept of probability. ${ }^{1}$

An analogy may very well be found between Huygens' aphorism and the conclusions traced within this study, conducted by one of the leading European centers of aortic open and endovascular surgery. The authors, in fact, seem to demonstrate what Huygens claimed: just as in gambling, nothing is known with certainty, but everything is determined with probability. In medicine, even if there are no certainties, it is possible to estimate the odds that certain events may actually occur.

Acute uncomplicated type B aortic dissection (TBAD) treated with medical therapy is a field with some open issues, which Kreibich and colleagues aimed to address with their retrospective study. ${ }^{2}$ Historically, the gold standard therapeutic option for acute uncomplicated TBAD has been aggressive medical therapy to achieve an 